\title{
SIEMENS VAI LASER WELDER INDUSTRIAL RESULTS ON A LARGE RANGE OF PRODUCT*
}

Hervé Thomasson ${ }^{1}$

\begin{abstract}
Siemens VAI has made an important Research \& Development effort since 10 years on laser welder field. The last step of this program was in 2010, the evolution of its laser welder range by implementing the solid state technology with laser cutting and welding. Since this step, 8 welders were produced by Siemens VAl. Now after more than 1 year of industrial feedback, the results are showing a high level of performances on very demanding processing lines for a large range of products from Silicon steel to High Strength Steel with DP and TRIP grades. This laser welder concept using laser cutting and welding through solid state laser source is also proposed by Siemens VAI for pickling lines and tandem mills with significant advantages compared to standard solution.
\end{abstract}

Keywords: Laser welder; Solid state technology; Silicon steel; High strength steel.

* Technical contribution to the 51st Rolling Seminar - Processes, Rolled and Coated Products, October $28^{\text {th }}$ to $31^{\text {st }}, 2014$, Foz do lguaçu, PR, Brazil. 


\section{SIROLL WELDER DEVELOPMENT PROGRAM}

An extensive R\&D program has been conducted by Siemens VAI in the field of welders for more than 10 years. In the 90's, the early stage of the programme was dedicated to developing a new "Flash Butt » welder concept (pickling entry section, fully continuous rolling mill ...) and a new « Mash Lap » welder concept (galvanizing line entry, continuous annealing, inspection lines ...).

The program was then pursued in 2000 with the development of the laser welding process. The first stage of development focused on light gauge (LW21L) for galvanizing lines, inspection lines... The development of the laser welder for heavy gauges $(\mathrm{LW} 21 \mathrm{H})$ was started in 2004 for thickness ranges from 1.00 to $7.00 \mathrm{~mm}$.

Through continued research efforts and always willing to be ahead in term of technology, Siemens VAI has now reached a new step with the integration in the welder of the solid state technology for its laser source. This laser source is replacing the $\mathrm{CO}^{2}$ resonator. The Solid state technology already used on other industry sectors like automotive, tailor blank welding... leads to different and significant advantages compared to the $\mathrm{CO}^{2}$ solution. The Solid state technology makes it possible to transmit the beam from the laser source to the process heads (cutting and welding) through optic fibre instead of using mirrors.

Laser welding machine of Siemens VAI proposes laser cutting operation which makes possible to have a perfect cutting operation on the whole range of steel grades and thickness and then a perfect preparation for the welding phase by laser.

\section{SOLID STATE TECHNOLOGY ADVANTAGES}

This new technological step gives a lot of benefits to steel producers with among others, a higher efficiency, lower consumptions, higher process speed for cutting and welding, easier maintenance with no mirror installed on the machine...

\subsection{Simple Beam Path Transportation}

By using optical fibre to transport the beam from the laser source to the process heads (for cutting and for welding), the customer does not have mirrors or beam switch on the machine. With this beam transportation system, the adjustment of the welder is very easy and the maintenance operations are reduced to almost nothing for the beam path. With this fiber technology, we have a "plug and play" system which avoids accurate and difficult adjustment of beam path. This is a key point for commissioning point and maintenance as it has been confirmed after commissioning and industrial feedback of last Siemens VAI projects. One fiber is connected on the cutting head and one on the welding head and both are connected on the other side to the laser source (Figure 1).

\footnotetext{
* Technical contribution to the 51st Rolling Seminar - Processes, Rolled and Coated Products, October $28^{\text {th }}$ to $31^{\text {st }}, 2014$, Foz do Iguaçu, PR, Brazil.
} 


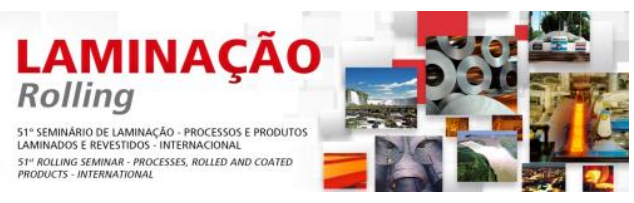

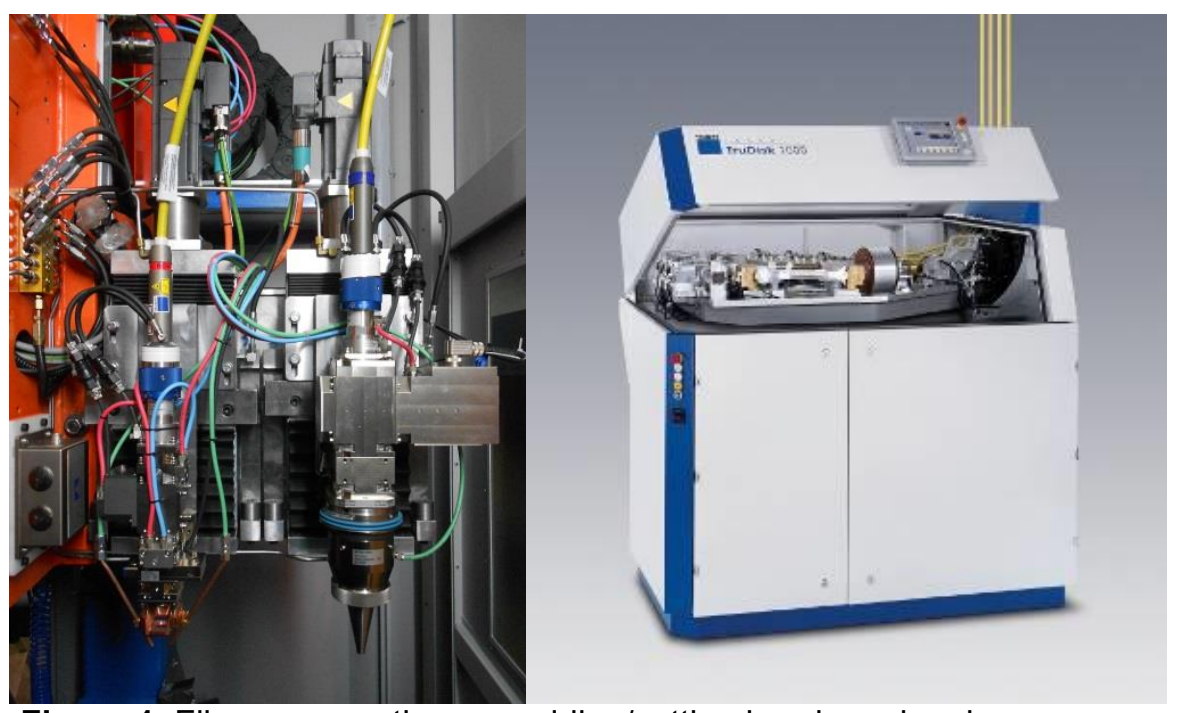

Figure 1: Fibers connection on welding/cutting heads and on laser source

With the length available for the fibres, it is possible to install the laser source separate from the welder. Therefore the laser source could be installed in a dedicated space or room which is not possible with $\mathrm{CO}^{2}$ technology. This makes possible to have a perfect control of the laser source environment and will improve drastically the life time of the laser source.

Additionally, without laser source on the machine, the space required by the machine mainly on the motor side of the line is reduced. This point could be a key aspect in case of lines being revamped where the space is often an important issue.

\subsection{Higher Efficiency and Lower Maintenance}

With a higher efficiency, it makes it possible to decrease electrical consumption and sizing of other systems like the cooling unit. At a same laser power level, installed electrical powers for the chiller and laser source are reduced by $50 \%$.

In term of maintenance, the maintenance level on the fiber system, with no overpressure system, no mirror, no check of internal part, is limited to a visual control without any dismounting operation.

For the laser source itself, the maintenance is drastically reduced compared to $\mathrm{CO}^{2}$ technology with a simple yearly maintenance. At a same laser power level, the using hourly cost (including maintenance gas, electrical consumption) is $80 \%$ less for solid state technology compared to $\mathrm{CO}^{2}$ technology.

\subsection{Higher Performance in Cutting and Welding}

One main point for the laser welding process is the preparation of the strip. Therefore the cutting operation is a key point. With laser, the cutting quality is perfect without deformation of the strip which is with mechanical shearing. There is no limitation in term of steel strength for the cutting capacity.

As a none-contact operation, there is no wear of the cutting tools. Therefore maintenance is almost zero compared to an heavy maintenance of mechanical shear with blade change and grinding.

Quality and reliability of cutting has been verified on the whole range of thickness for the 2 applications LW21L (CGL/CAL/RCL) and LW21H (PL/PLTCM) (see cutting quality on Figure 2).

* Technical contribution to the 51st Rolling Seminar - Processes, Rolled and Coated Products, October $28^{\text {th }}$ to $31^{\text {st }}, 2014$, Foz do Iguaçu, PR, Brazil. 
effort with the goal to always propose better solutions to our customers.

When thinking about better solutions, with its field experience and industrial feedback, Siemens is always thinking of different aspects from installation, return on investment (ROI), consumption, maintenance to service support and last evolution of our laser welders is fully adhering to this policy with higher efficiency and performance level, easier installation, reduced maintenance. And with a lower investment level, this new laser welder evolution represents important gains for the customer.

But of course, this is not an end and Siemens will pursue its goal of always proposing better products and better solutions for its customers to support them for new challenges.

* Technical contribution to the 51st Rolling Seminar - Processes, Rolled and Coated Products, October $28^{\text {th }}$ to $31^{\text {st }}$, 2014, Foz do Iguaçu, PR, Brazil. 